\title{
REVIEW \\ Psychosocial aspects of spinal cord injury pain: a meta-analysis
}

\author{
J Tran ${ }^{1,3}$, DS Dorstyn ${ }^{1,3}$ and ALJ Burke ${ }^{1,2}$
}

Study design: Meta-analysis.

Objectives: Although the association between modifiable psychosocial factors and spinal cord injury (SCI) pain has been identified, the full range of psychological and social difficulties for those who experience acute and/or persistent pain remains unclear. This metaanalysis consolidates the available evidence, using the International Classification of Functioning, Disability and Health (ICF) as a reference framework.

Methods: Nineteen studies that examined persistent neuropathic, nociceptive or mixed pain subtypes in adults with a SCl (newly acquired and chronic; $N_{\text {participants }}=2934$ ) were identified from electronic database searches. Standardised mean differences between $\mathrm{SCl}$ pain and no-pain groups on self-reported psychosocial outcomes were calculated, along with $95 \%$ confidence intervals, fail-safe Ns and heterogeneity statistics.

Results: Twenty individual outcomes were grouped into nine ICF-related categories. Emotional functions were the most frequent (100\%) psychosocial outcomes assessed, with pain contributing to heightened stress $(d=-0.85)$, depression $(d=-2.49)$ anxiety ( $d$ range $=-0.85$ to -1.45 ), poor self-efficacy $(d=-0.77$ ), lowered wellbeing ( $d$ range $=-0.67$ to -1.02 ) and decreased use of adaptive coping, such as illness acceptance $(d=-0.85)$. Activity limitations and participation restriction were examined by seven studies (43\%), although these findings were largely characterised by single studies.

Conclusions: Multicomponent treatments that target mood disturbance and foster community connections are important in SCl pain management. However, to improve the comparability of future studies, SCl pain research must adopt definitions of pain consistent with the International Spinal Cord Injury Pain Classification along with validated outcomes that map onto the ICF framework.

Spinal Cord (2016) 54, 640-648; doi:10.1038/sc.2016.66; published online 10 May 2016

\section{INTRODUCTION}

Most individuals with a spinal cord injury (SCI) will experience neuropathic and/or nociceptive (i.e. musculoskeletal, visceral) pain of varying intensity, quality and constancy. ${ }^{1-3}$ For many, this results in a pain continuum, from acute biomedical treatment through to management of persistent pain., ${ }^{4,5}$ SCI pain management is further complicated by a multitude of cognitive, emotional, behavioural and social factors that can adversely affect, or buffer, the pain experience. ${ }^{6,7}$ To ensure optimal pain management, an investigation of the psychosocial characteristics of both acute and persistent pain conditions following SCI is therefore required. ${ }^{6}$

The dynamic influence of psychological and social factors in SCI pain is best depicted by the International Classification of Functioning, Disability and Health (ICF) core sets for SCI care, which outline the dynamic interaction between body functions (i.e. secondary medical complications, such as pain), an individual's personal or psychological functioning, and their work, family and social interactions. ${ }^{8-10}$ Consistent with the ICF framework, studies have identified an association between severity of SCI pain and degree of mood disturbance (including depression and anxiety), during the subacute phase of SCI. ${ }^{11,12}$ However, relationships between pain severity and affective distress may change over time. ${ }^{13}$ Indeed, community SCI samples (i.e. mean time since injury 17 years) reporting substantial pain do not necessarily have concurrent depression. ${ }^{14}$ Indeed, Raichle et $a l .{ }^{15}$ found that pain severity on its own explained only $14 \%$ of the variance in mental health status among adults with mixed (e.g. shoulder, lower back) and persistent pain subtypes, suggesting that responses to SCI pain are complex. Another psychological variable that impacts on post-injury pain is one's degree of confidence in performing activities despite pain. ${ }^{14,16}$ Whether this self-efficacy remains a determinant of pain behaviour and disability in the longer term is, however, still to be established. ${ }^{6}$

The ICF also defines psychosocial difficulties as activity limitations and participation restrictions related to an individual's community and social functioning. ${ }^{8,9}$ For example, Donnelly and Eng ${ }^{17}$ found that pain intensity was significantly associated with one's ability to reintegrate into the community in the first 6 months post SCI. Longitudinal studies have also demonstrated that those with pain report less social interaction and support compared with pain-free peers, ${ }^{18}$ and lower satisfaction with their participation in daily self-care activities, family roles and relationships. ${ }^{19}$ Notably, these studies have operationalised participation in various ways, highlighting the multidimensionality of this concept. ${ }^{20}$

${ }^{1}$ School of Psychology, University of Adelaide, Adelaide, SA, Australia and ${ }^{2}$ Psychology Department, Royal Adelaide Hospital, Adelaide, SA, Australia

${ }^{3}$ These authors contributed equally to this work.

Correspondence: Dr DS Dorstyn, School of Psychology, University of Adelaide, North Terrace campus, Adelaide, SA 5005, Australia.

E-mail: diana.dorstyn@adelaide.edu.au

Received 17 December 2015; revised 24 March 2016; accepted 24 March 2016; published online 10 May 2016 


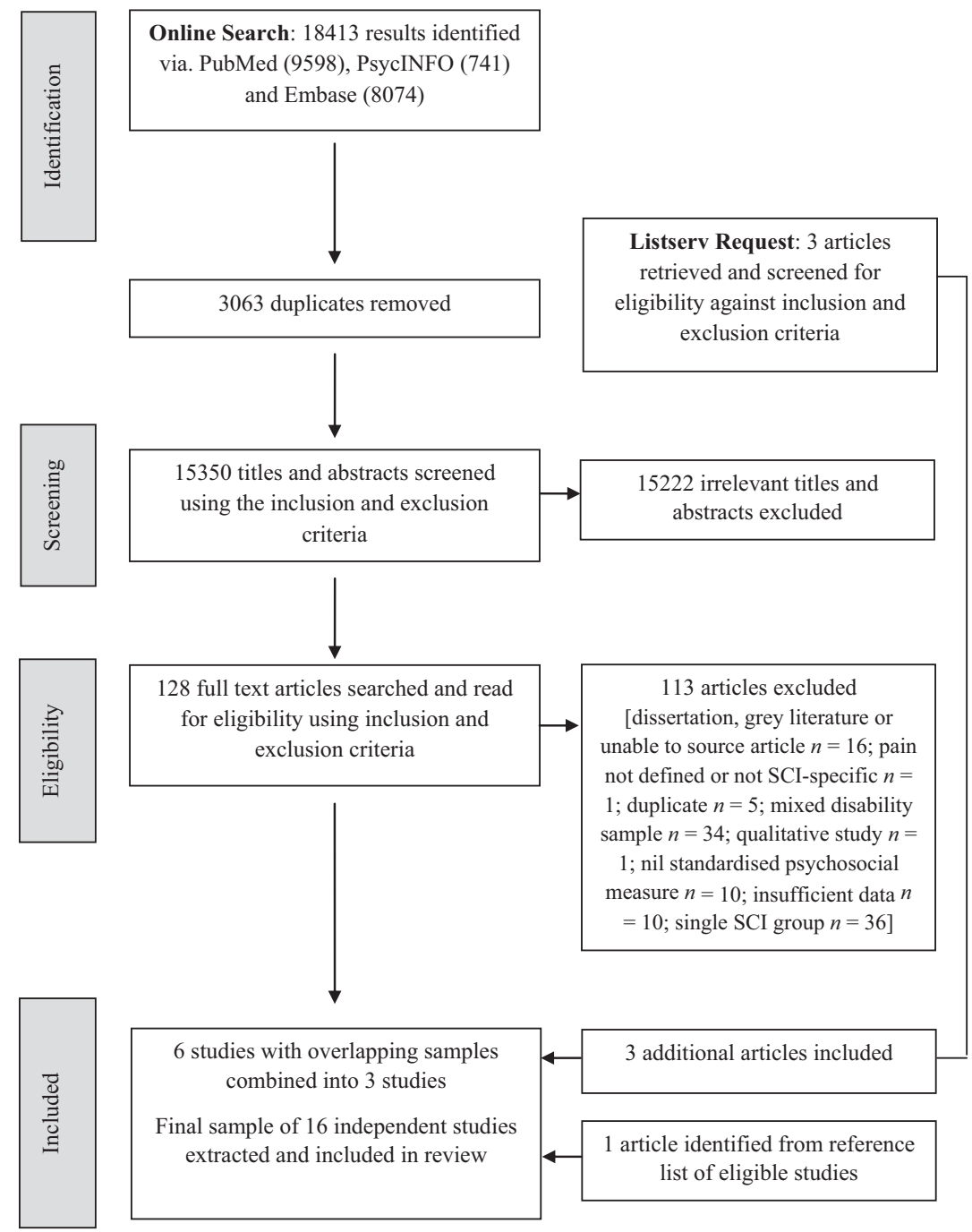

Figure 1 Flow chart of the study selection process.

In summary, the ICF can be used as a reference to define the psychosocial issues encountered by individuals who report pain following an acquired SCI. This paper will quantitatively review the available data to map the onset and maintenance of psychosocial difficulties in SCI pain, as predicted by the ICF.

\section{MATERIALS AND METHODS}

\section{Literature search}

An online search of the Embase, PsycINFO and PubMed databases was undertaken to source eligible studies that examined psychosocial functioning in participants with and without SCI pain. Database searches were undertaken for the period between January 1960 (coinciding with the earliest date when MeSH terms for 'pain' were introduced) to September 2015. A research librarian was consulted during this process to improve accuracy and relevance of the search terms (see logic grids provided in online Supplementary Material). The initial search criteria was kept deliberately broad (i.e. did not specify psychosocial variables) to ensure that all potentially relevant articles were captured. Further, requests for relevant published data were made through the listserv for the American Psychological Association's Division 22 (Rehabilitation Psychology). Finally, additional studies were identified from a manual search of the reference lists of all eligible studies.

\section{Study eligibility}

Studies were included in the current meta-analysis if they: (a) recruited individuals, aged 16 years or older (the lowest common entry age specified for adult services ${ }^{21}$ ) who had sustained an SCI, and reported experiencing pain (either directly related to SCI pathology (i.e. neuropathic, nociceptive pain) or post-injury pain of unknown origin); ${ }^{2,3}$ (b) used an SCI control group with no pain; (c) explored the psychosocial functioning of both groups via standardised assessment tools; (d) provided quantitative data that permitted the calculation of Cohen's $d$ effect size (i.e. group means and s.d.'s, $t$-statistic, point biserial correlation coefficient, exact $P$-values); ${ }^{22,23}$ and (e) were published in English. For the purpose of this review, psychosocial outcomes were defined as measures of psychological state (affective or behavioural) or the social environment (e.g. social support, community resources) that were considered modifiable or amenable to change, in the context of cognitive behavioural models of SCI pain. ${ }^{14}$ Studies were excluded if they examined a mixed disability group, where SCI pain data could not be separately extracted, or if they examined psychological constructs that may not be amenable to treatment (e.g. traitbased measures). Studies were also ineligible if they reported multivariate models, which are problematic for effect size interpretation because of their use of different combinations of predictor and outcome variables. ${ }^{23}$ The first author (JT) carried out the initial review of study titles, with the second author (DD) independently assessing abstracts using the aforementioned inclusion criteria. Disagreements were resolved by consensus decision. 
An initial 18413 articles were identified via the database searches, with 19 studies meeting the eligibility criteria (see Figure 1 ). This included six studies with overlapping samples, or two studies each by Norrbrink Budh et al. ${ }^{24}$ Norrbrink Budh and Osteraker, ${ }^{25}$ Putzke et al. ${ }^{26,27}$ and Rintala et al. ${ }^{28,29}$ However, only the single studies from Norrbrink Budh et al. ${ }^{24}$ and Putzke et al. ${ }^{26}$ met the minimum inclusion criteria, whereas the phase 1 data from Rintala et al. ${ }^{29}$ was used as it comprised a larger sample size. This resulted in a final sample of 16 independent studies. ${ }^{11,18,24,26,29-40}$

\section{Data extraction and organisation}

In accordance with the Preferred Reporting Items for Systematic Reviews and Meta-Analyses, ${ }^{41}$ data were collected with a purposely designed data extraction form. This included information relating to: study characteristics (e.g. country, sample recruitment source); sample demographics (e.g. age, sex, ethnicity, relationship and employment status); injury characteristics (e.g. time since injury, injury cause, SCI pain type); and statistical data (e.g. means and s.d.'s for individual measures of psychosocial functioning).

For ease of data interpretation, individual psychosocial measures were grouped according to concepts outlined in the ICF core sets for SCI. ${ }^{8,10}$ This included Geyh et al.'s ${ }^{10}$ elaboration of the personal domain into five subdomains: thoughts and beliefs, personal history and biography, feelings, patterns of experience and behaviour, and life satisfaction. ${ }^{10}$ Activity and participation limitations were defined as: economic self-sufficiency, informal social relationships, community life and family relationships. ${ }^{8}$

\section{Data preparation}

Before data analysis, the data for five studies required recalculation. First, three independent studies recruited multiple groups based on pain intensity (i.e. no pain vs mild, moderate or severe pain) or pain persistence (i.e. no pain vs intermittent or continuous pain). ${ }^{24,29,35}$ The data for each study was therefore pooled to reflect two distinct and consistent groups: SCI pain and SCI no pain. Similarly, where data were provided separately for subgroups (i.e. participants with paraplegia vs tetraplegia), ${ }^{32}$ the means and s.d.'s were pooled to provide an overall score for individuals with SCI pain and no pain. Where only median values and ranges were reported, ${ }^{24}$ these statistics were converted to estimated means and s.d. ${ }^{42}$ Fourth, studies that provided either point biserial correlation coefficients, ${ }^{18}$ group means and s.e. ${ }^{31} P$-value from a $\chi^{2}$ analysis ${ }^{36}$ or $t$-tests ${ }^{40}$ were converted to effect size $d$ using Wilson's calculator. ${ }^{43}$ Finally, the direction of individual standardised measures (e.g. Beck Depression Inventory) were rescaled to conform to the effect size rule adopted in this meta-analysis: negative values indicated that the SCI pain group reported poorer psychosocial functioning in comparison with pain-free peers.

\section{Data analysis}

Meta-analysis was chosen as the methodology due to its demonstrable benefits in evidence-based practice. ${ }^{44}$ This includes the ability to draw conclusions about statistical significance from several studies that have conflicting results in addition to its statistical power: the accumulated results of a meta-analysis can provide a more correct estimate of effect magnitude than the analysis of any single study. ${ }^{23,45}$

Data were analysed using Comprehensive Meta-analysis Software (version 3.0; Biostat Inc., Englewood, NJ, USA). Cohen's $d,{ }^{22}$ which provides an estimate of the standardised difference between two groups (i.e. SCI pain vs SCI no pain), was the primary effect size estimate used in this study. Importantly, most studies reported necessary means and s.d.'s, allowing consistency in the calculation of effect sizes. ${ }^{23}$ Effect sizes were interpreted according to Cohen's ${ }^{22}$ proposed guidelines: $0.2,0.5$ and 0.8 equating to small, medium and large group differences, respectively.

Effect sizes were calculated in several stages. First, Cohen's $d$ was calculated for each individual psychosocial measure used by a study. Second, studies that used the same psychosocial outcome and examined the same stage of SCI (i.e. acute vs chronic SCI) were pooled. Before being pooled, studies were weighted by their inverse variance $\left(d_{\mathrm{w}}\right)$, or inverse of the s.e. This weighting method compensates for the phenomenon that small sample sizes are generally associated with greater variability. 23,45
The precision of each effect size estimate was determined by calculating $95 \%$ confidence intervals (CIs) and $P$-values for both individual and weighted $d s{ }^{46}$ In addition, publication bias was assessed using the fail-safe N-statistic (Nfs). ${ }^{47}$ The calculation of Nfs estimates the hypothetical number of unpublished studies required to render a $d$ value as meaningless (i.e. equating to a small effect or $d<0.20$ for this review). ${ }^{47}$ The higher the Nfs value, the more likely that $d$ can be considered to be robust. For the purpose of this meta-analysis, an $\mathrm{Nfs}$ value was considered appropriate if the value exceeded the number of pooled studies that contributed to a weighted $d$ for a particular measure (i.e. Nfs $>N_{\text {studies }}$ ).

The consistency of results between studies in this meta-analysis was examined with the $I^{2}$ index. ${ }^{48}$ The larger the $I^{2}$ value, the greater the degree of heterogeneity across true effect size estimates. ${ }^{45,48}$ The conservative randomeffects model was applied for these statistical analyses. This model assumes that the true effect is similar, but not identical, across individual studies, ${ }^{45}$ which suits the clinical and methodological diversity that characterises SCI pain research. ${ }^{2,3,5,6}$

A combination of statistics was therefore considered when interpreting the results obtained from this meta-analysis. Specifically, an ICF subdomain was considered to be clinically and statistically important if the weighted effect size $\left(d_{\mathrm{w}}\right)$ : (a) represented a medium to large $(d \geqslant 0.50)$ mean group difference between the SCI pain and no pain groups; (b) the associated 95\% CI did not span zero; and (c) the Nfs score suggested that the findings were unlikely to be compromised by publication bias (i.e. $\mathrm{Nfs}>N_{\text {studies }}$ ). The interpretation of effect sizes was also considered within the context of between-study heterogeneity.

\section{RESULTS}

\section{Study characteristics}

The 16 independent studies included in this meta-analysis provided data for 1658 individuals with acute or persistent pain and 1276 painfree peers (see Table 1). In all cases, pain was assessed by standardised outcomes measures, including the McGill Pain Questionnaire and West-Haven Yale Multidimensional Pain Inventory. Four studies $^{18,24,35,39}$ supplemented pain self-reports with general medical assessment or neurological interview. Visual and numerical rating scales were primarily used to rate pain severity and frequency $\left(N_{\text {studies }}=7\right)$.

The vast majority of the data provided for this meta-analysis originated from the United States of America $\left(N_{\text {studies }}=6\right)$ and Europe $\left(N_{\text {studies }}=5\right)$, followed by Australia $\left(N_{\text {studies }}=2\right)$, Asia $\left(N_{\text {studies }}=2\right)$ and Canada $\left(N_{\text {studies }}=1\right)$. Participants were primarily sourced from a single SCI centre or unit, with studies also using regional or national data sets, including the Stockholm SCI database, ${ }^{39}$ Norwegian Survey Archive $^{34}$ and SCI model system ${ }^{26,36}$ The two largest studies ${ }^{37,39}$ contributed to $41 \%$ of the overall sample size (i.e. combining SCI with and without pain). Most studies provided cross-sectional data, with longitudinal designs adopted by four studies. ${ }^{18,26,29,33}$

A total of 20 standardised, self-report psychosocial measures were used across the 16 independent studies. The 12- or 36-item Short Form Health Survey $\left(N_{\text {studies }}=6\right)$, a quality of life measure routinely used in medical research, ${ }^{49}$ was most commonly used to assess physical and mental health functioning. Questionnaires were primarily administered in a clinical setting or by a mailout survey $\left(N_{\text {studies }}=8\right)$, with the remainder administered as part of a semistructured interview $\left(N_{\text {studies }}=8\right)$.

\section{Sample characteristics}

As seen in Table 1, the majority of individuals were male, middle-aged, married or partnered, unemployed and Caucasian; although these data were not routinely reported. Participants had been living with their SCI for an average of 12 years, with traumatic SCIs (e.g. vehicular accidents, falls) the most common aetiology. Time since injury was 
Table 1 Sociodemographic and injury details for participants

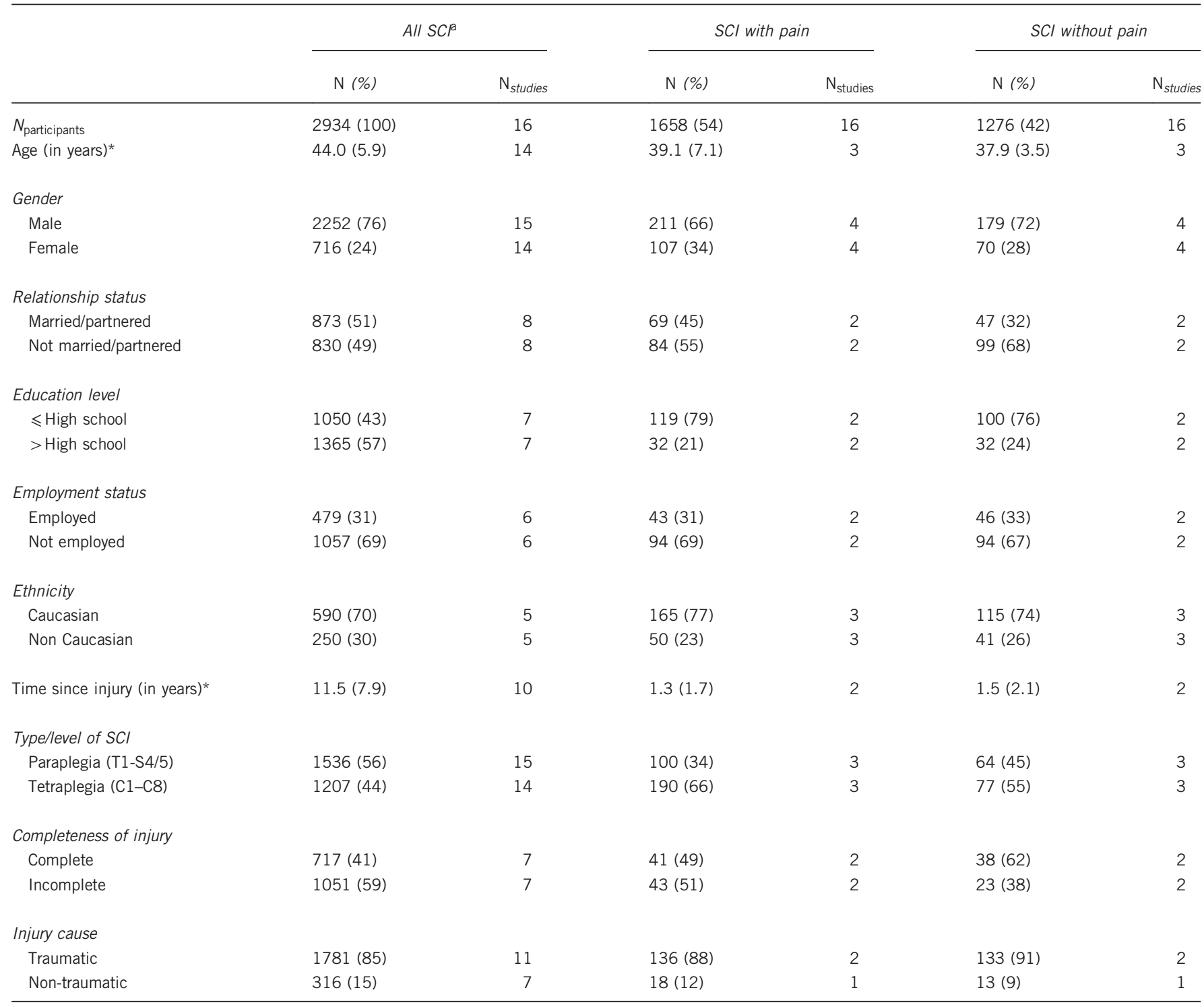

Abbreviation: $\mathrm{SCl}$, spinal cord injury.

Note: $N_{\text {participants }}$, number of participants providing data; $N_{\text {studies }}$, number of studies providing data. Figures presented are $N(\%)$, except where indicated by * to be $M$ (s.d.).

aValues are not the sum of participants with and without pain, due to missing or incomplete data reported.

not routinely specified. Only a few studies provided separate demographic information for participants with and without SCI pain. ${ }^{26,29,38}$

Participants reported experiencing neuropathic (at-level and below-level) pain and/or nociceptive (musculoskeletal, visceral) pain. The two acute SCI studies reported ongoing pain from injury onset. $^{11,36}$ The remaining 14 studies examined pain in the longer term and described this pain as persistent, although pain duration was not usually specified. Where this detail was provided, pain was experienced at a minimum of four 2-week periods during the past 12 months, to more than 6 months. Wollaars et al. ${ }^{40}$ provided information about pain treatments, with $41 \%$ of their sample having used physical-based therapy (i.e. yoga, massage, physiotherapy) and $10 \%$ requiring prescription medication (i.e. gabapentin).

\section{Psychosocial function}

As seen in Figure 2, the impact of pain on psychological status was routinely assessed (100\% of studies), followed by activity limitations and participation restrictions (44\% of studies). Statistical homogeneity $\left(I^{2}=0.00, P>0.05\right)$ was found for most ICF subdomains, although this likely reflects the small number of studies contributing to this data $\left(N_{\text {studies }}<4\right)$. In comparison, the 14 studies that assessed the broad ICF concept of feelings used seven individual psychological measures to assess depression, anxiety and/or general mental health status, across a range of sample sizes $\left(N_{\text {range }}=88-767\right)$. It is therefore not surprising that this subdomain demonstrated inconsistency in effect size estimates.

\section{Personal}

Despite all studies assessing the impact of SCI pain on psychological status, few used the same outcome measure (Table 2). Significant and large group differences for thoughts and beliefs were noted in both the acute and chronic stages of SCI pain, although these findings were restricted to two small-scale studies. ${ }^{11,29}$ Specifically, participants with pain reported heightened levels of stress (Perceived Stress Scale) 


\begin{tabular}{|c|c|c|c|c|c|c|c|c|c|}
\hline \multirow[t]{2}{*}{ ICF domain } & \multirow[t]{2}{*}{ Subdomain } & \multirow[t]{2}{*}{$N_{\text {studies }}$} & \multirow{2}{*}{$N_{\text {participants }}$} & \multirow[t]{2}{*}{$d \mathrm{w}$} & \multicolumn{2}{|c|}{$95 \%$ CI } & \multirow[t]{2}{*}{$P$} & \multirow[t]{2}{*}{$N_{\mathrm{fs}}$} & \multirow[t]{2}{*}{$I^{2}$} \\
\hline & & & & & Lower & Upper & & & \\
\hline \multirow{4}{*}{$\begin{array}{r}\text { Activities and } \\
\text { participation }\end{array}$} & Economic self & 1 & 172 & -0.57 & -0.87 & -0.27 & 0.000 & 2 & - \\
\hline & 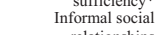 & 3 & 620 & -0.43 & -0.61 & -0.26 & 0.000 & 3 & $0 \%$ \\
\hline & $\begin{array}{l}\text { relatoonships } \\
\text { Community life }\end{array}$ & 4 & 1212 & -0.28 & -0.40 & -0.17 & 0.000 & 2 & $0 \%$ \\
\hline & Family relationships & 2 & 260 & 0.00 & -0.28 & 0.28 & 0.989 & 2 & $0 \%$ \\
\hline \multirow[t]{5}{*}{ Personal } & Thoughts and beliefs" & 2 & 143 & -0.81 & -1.31 & -0.31 & 0.002 & 6 & $0 \%$ \\
\hline & Feelings* & 14 & 1907 & -0.54 & -0.84 & -0.26 & 0.000 & 24 & $86.2 \%$ \\
\hline & $\begin{array}{l}\text { Personal history and } \\
\text { hiograt }\end{array}$ & 1 & 37 & -0.59 & -1.32 & 0.15 & 0.120 & 2 & - \\
\hline & $\begin{array}{l}\text { sof experiencine } \\
\text { onthence }\end{array}$ & 3 & 363 & -0.47 & -0.72 & -0.21 & 0.000 & 4 & $0 \%$ \\
\hline & $\begin{array}{l}\text { and behaviour } \\
\text { Life satisfaction }\end{array}$ & 3 & 989 & -0.41 & -0.54 & -0.27 & 0.000 & 3 & $0 \%$ \\
\hline
\end{tabular}

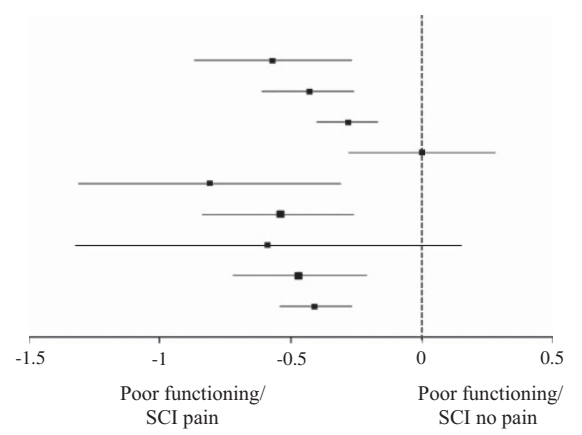

Figure 2 Forest plot with effect sizes and associated statistics per ICF domain. *Effect size met the study criteria: $d>0.50 ; 95 \%$ Cls $\neq 0$; Nfs $>N_{\text {studies }}$.

and lower levels of self-efficacy in relation to managing self-care activities (Moorong Self-Efficacy Scale) compared with their pain-free counterparts. In the feelings subdomain, an individual measure of anxiety and depression-the Hospital Anxiety and Depression Scale_-produced the largest effect estimate. However, related measures of depression severity or symptomatology were not significant (i.e. BDI, CES-D, PHQ-9). General wellbeing (i.e. Short Form Health Survey-12 item, Kessler Mood Inventory) was also affected, with pain negatively impacting on mood throughout the course of SCI. In comparison with peers without pain, individuals with acute SCI pain also displayed poor patterns of experience and behaviour based on a validated coping measure, the Spinal Cord Lesion-Related Coping Strategies. ${ }^{11,50}$ This included less acceptance or revaluation of life values postinjury, and a tendency towards dependent behaviour (e.g. reduced efforts to behave independently). The remaining measures in this personal domain, which included post-traumatic growth and resilience, illness cognitions and satisfaction with life, were confounded by publication bias ( $\left.\mathrm{Nfs}>N_{\text {studies }}\right)$.

\section{Activity and participation}

Group differences in degree of activity and participation, at home and in the community, were examined by seven studies, all involving adults with persistent SCI pain (Table 3). The Economic Selfsufficiency subscale from the Craig Handicap and Reporting Technique was the only measure to meet the criteria for clinical significance (i.e. $d>0.50 ; 95 \%$ CIs $\neq 0$; Nfs $>N_{\text {studies }}$ ). Specifically, individuals with pain reported reduced ability to sustain socioeconomic activity and independence (defined as hours per week spent in paid employment and educational activities), in comparison with peers without pain. No firm conclusions can be drawn in relation to the impact of SCI pain on interpersonal relationships and different aspects of community life given the small $\mathrm{Nfs}$ statistics.

\section{DISCUSSION}

This meta-analysis synthesised the data from 2934 participants across 16 studies to describe and examine the psychosocial functioning of persons living with SCI pain. The dynamic interaction between psychosocial domains in the SCI pain experience is depicted in Figure 3, which maps the findings of the present review onto the ICF. As demonstrated, the most frequent difficulties associated with pain were psychological in nature, regardless of whether pain was experienced in the acute or chronic stages of SCI. Pain was also identified as a significant barrier to earning potential, or one's ability to be financially independent. This evidence was, however, limited in quantity.
The results are congruent with earlier systematic and narrative reviews, which suggest that psychosocial difficulties commencing in the acute phase of an SCI can become chronic without the appropriate treatment. ${ }^{6,51-53}$ The results also highlight avenues for further research. Specifically, the need to explore influences on social and community participation for people with an SCI. Attitudinal barriers and service accessibility are key barriers that can predict both physical and mental wellbeing, post SCI. ${ }^{54}$ Temporal fluctuations in the stability of structural and perceived social support can also influence postinjury adjustment outcomes. ${ }^{55,56}$ However, the relative impact of specific support constructs (i.e. structural vs perceived social support), in addition to interaction effects between support services and pain remain unclear. ${ }^{55}$

\section{Clinical implications}

Given that psychosocial factors are associated with SCI pain, biopsychosocial case formulations are warranted. Accurate case formulations can help identify factors contributing to, and effecting, the pain experience; in turn, highlighting key psychosocial targets for SCI pain management. ${ }^{57}$ This might include activity pacing and scheduling of pleasant activities, behavioural skills training and/or cognitive interventions to challenge unhelpful thoughts and reinforce adaptive coping, thereby helping individuals feel more equipped to manage the physical and emotional consequences of their SCI.,5 Rehabilitation efforts to promote engagement in meaningful community activities can also contribute to health-related quality of life. ${ }^{58}$

Case formulations require accurate identification of those individuals at risk of experiencing poor psychosocial outcomes. ${ }^{57}$ Validated self-reported health indices for the SCI group include condition-specific measures, such as the Spinal Cord Lesion Coping Strategies Questionnaire ${ }^{50}$ and Moorong Self-Efficacy Scale, ${ }^{59}$ which assess passive and active behavioural coping. The Initiative on Methods, Measurement and Pain Assessment in Clinical Trials (IMMPACT), also provides a list of outcome measurements across biopsychosocial life domains, including emotional functioning. ${ }^{60}$ Recommended rating scales are the Beck Depression Inventory and Profile of Mood States. ${ }^{60}$

The small number of eligible studies for this review also points to the need for having standardised and consistent collection and reporting of pain in the SCI population. The various subtypes of SCI pain can be challenging to classify. ${ }^{2}$ In recognition of this need, the International Spinal Cord Injury Pain Classification has been developed. ${ }^{2}$ Future research should also consider the International Basic SCI Pain Data set, which contains clinically core questions to formulate a probable diagnosis of pain type. ${ }^{3}$ This includes pain duration, location, subtype (i.e. ability to experience acute, 
Table 2 Cohen's $d$ effect sizes for psychosocial measures categorised under ICF personal domain $\left(N_{\text {studies }}=16\right)$

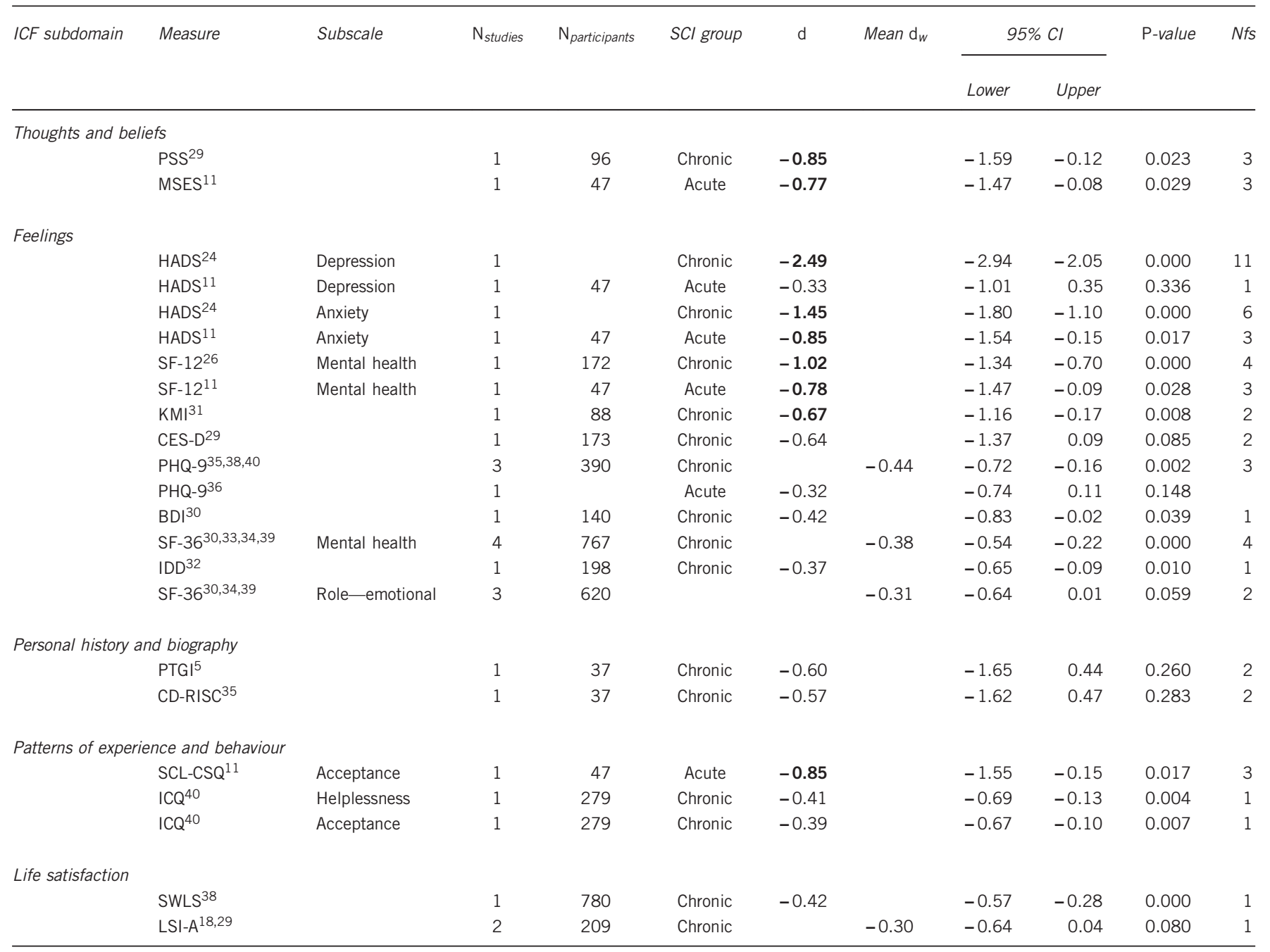

Abbreviations: $95 \% \mathrm{Cl}$, lower and upper limit of $95 \%$ confidence interval; $d$, Cohen's $d$; $d_{w}$, weighted mean effect size (note: weighting only applied to effect sizes based on two or more studies); ICF, International Classification of Functioning, Disability and Health; Nfs, approximate fail-safe $N ; N_{\text {participants, }}$, number of participants providing data; $N_{\text {studies }}$, number of studies providing data; ICF, International Classification of Functioning, Disability and Health; Nfs, approximate fail-safe $N$; $N_{\text {participants, }}$ number of participants providing data; $N_{\text {studies }}$, number of studies providing data; $\mathrm{SCl}$, spinal cord injury.

Measure abbreviations: BDI, Beck Depression Inventory; CD-RISC, Connor-Davidson Resilience Scale; CES-D, Centre of Epidemiological Studies Depression Scale; HADS, Hospital Anxiety and Depression Scale; ICQ, IIIness Cognition Questionnaire; IDD, Inventory to Diagnose Depression; KMI, Kessler Mood Inventory; LSI-A, Life Satisfaction Index; MSES, Moorong Self-Efficacy Scale; PHQ-9, Patient Health Questionnaire; PSS, Perceived Stress Scale; PTGI, Post-Traumatic Growth Inventory; SCL-CSQ, Spinal Cord Lesion-Related Coping Strategies; SF-12/SF-36, Short Form Health Survey; SWLS, Satisfaction with Life Scale.

Numbers in bold reflect statistically and clinically significant effect sizes: $d>0.50 ; 95 \% \mathrm{Cls} \neq 0$; Nfs $>N_{\text {studies }}$.

Negative $d$ value indicates poorer psychosocial functioning for the $\mathrm{SCl}$ pain group. Study reference in superscript.

intermittent and persistent pain simultaneously), ${ }^{2}$ and biopsychosocial aspects (e.g. perceived pain interference with activities, mood and sleep). Although the data set requires further validation, it offers promise as a consensus taxonomy.

\section{Study limitations}

A number of methodological limitations warrant consideration when interpreting the results of this meta-analysis. First, although the electronic search criteria were broad, the search was restricted to studies published in the English language. Caution must also be taken when interpreting these results owing to the small number of studies contributing to this meta-analysis; studies that also relied on individual measures of psychosocial functioning and small sample sizes, thereby limiting statistical power. ${ }^{45}$

The pooling of effect sizes in this review also needs consideration. Although the ICF can be used to guide the selection of clinical measures, and, in turn, improve the consistency of data collection in
SCI research, further research is needed to determine which psychological outcomes best map onto ICF domains of functioning. ${ }^{10,61}$ The difficulty is that psychological constructs such as depression are heterogenous, with symptom coverage (i.e. cognitive, somatic, affective) and duration (i.e. 'recent' symptoms in past week or fortnight vs 'usual symptoms') varying across different measures. This was highlighted by the range of effect sizes associated with the individual measures of depression in this meta-analysis. The crossmeasure equivalence of available depression severity ratings (i.e. HADS, SF-12), screening tools (i.e. PHQ-9, IDD) and diagnostic measures (i.e. Structured Clinical Interview for DSM disorders) also warrants examination. ${ }^{62,63}$ Indeed, the utility of severity 'cutoff scores for 'probable depression' based on self-report has only recently been explored. ${ }^{64}$

Another limitation relates to the sample characteristics. Given that the sample had a greater proportion of males compared with females, the findings may be limited in their generalisability to both genders. 
Table 3 Cohen's $d$ effect sizes for psychosocial measures categorised under ICF activities and participation domain $\left(N_{\text {studies }}=7\right)$

\begin{tabular}{|c|c|c|c|c|c|c|c|c|c|c|}
\hline \multirow[t]{2}{*}{ ICF subdomain } & \multirow[t]{2}{*}{ Measure } & \multirow[t]{2}{*}{ Subscale } & \multirow[t]{2}{*}{$\mathrm{N}_{\text {studies }}$} & \multirow[t]{2}{*}{$\mathrm{N}_{\text {participants }}$} & \multirow[t]{2}{*}{$d$} & \multirow[t]{2}{*}{ Mean $\mathrm{d}_{w}$} & \multicolumn{2}{|c|}{$95 \% \mathrm{Cl}$} & \multirow[t]{2}{*}{$P$-value } & \multirow[t]{2}{*}{ Nfs } \\
\hline & & & & & & & Lower & Upper & & \\
\hline \multicolumn{11}{|c|}{ Economic self-sufficiency } \\
\hline & $\mathrm{CHART}^{26}$ & Economic self-sufficiency & 1 & 172 & -0.57 & & -0.88 & -0.27 & 0.000 & 2 \\
\hline \multicolumn{11}{|c|}{ Social relationships } \\
\hline \multicolumn{11}{|l|}{ Community life } \\
\hline & $\mathrm{CIQ}^{18}$ & Social integration & 1 & 147 & -0.46 & & -0.87 & -0.06 & 0.025 & 1 \\
\hline & & Productive activity & 1 & 147 & 0.05 & & -0.35 & 0.45 & 0.803 & 1 \\
\hline & $\mathrm{CHART}^{26,18}$ & Social integration & 2 & 285 & & -0.32 & -0.56 & -0.08 & 0.008 & 1 \\
\hline & $\mathrm{CHART}^{26}$ & Occupational & 1 & 147 & -0.16 & & -0.46 & 0.14 & 0.308 & 0 \\
\hline \multicolumn{11}{|c|}{ Family relationships } \\
\hline & $\mathrm{FSS}^{18}$ & & 1 & 113 & -0.10 & & -0.49 & 0.28 & 0.595 & 0 \\
\hline
\end{tabular}

Abbreviations: $95 \% \mathrm{Cl}$, lower and upper limit of $95 \%$ confidence interval; $d$, Cohen's $d$; $d_{w}$, weighted mean effect size (note: weighting only applied to effect sizes based on two or more studies); ICF, International Classification of Functioning, Disability and Health; Nfs, approximate fail-safe $N$; $N_{\text {participants, }}$ number of participants providing data; $N_{\text {studies, }}$, number of studies providing data. Measure abbreviations: CHART, Craig Handicap Assessment and Reporting Technique; CIQ, Community Integration Questionnaire; RNL, Reintegration to Normal Living Index; FSS, Family Satisfaction Scale; SF-36, Short Form Health Survey.

Numbers in bold reflect statistically and clinically significant effect sizes: $d>0.50 ; 95 \% \mathrm{Cls} \neq 0$; Nfs $>N_{\text {studies }}$

Negative $d$ value indicates poorer psychosocial functioning for the SCI pain group. Study reference in superscript.

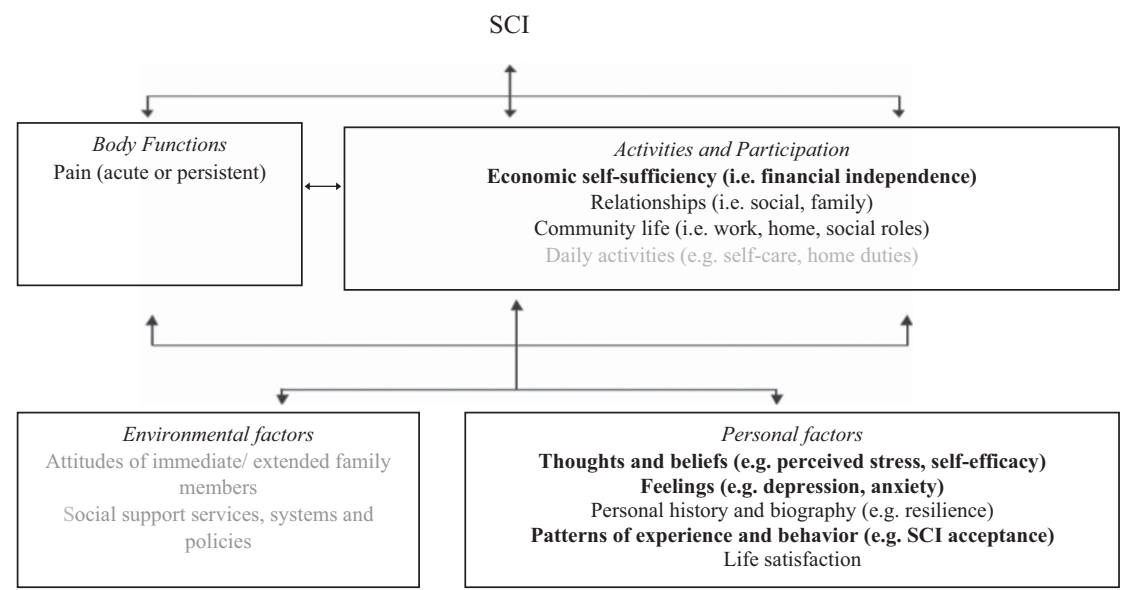

Figure 3 ICF psychosocial domains linked to the SCl pain experience based on the current findings. Note: Bold text indicates subdomains identified as clinically and statistically significant from this study. Normal text indicates subdomains identified, but not found to be clinically and/or statistically significant. Grey text indicates subdomains identified in $\mathrm{SCl}$ research that may have a significant role in $\mathrm{SCl}$ pain, but were not specifically examined by included studies.

It is important to note that the 3:1 male:female ratio is consistent with global prevalence patterns of SCI. ${ }^{21}$ Moreover, there is evidence to suggest that males and females with SCI describe their pain similarly. ${ }^{65,66}$ The studies contributing to this meta-analysis also predominantly originated from Western countries, and, as such, may not be applicable to non-Caucasian groups. Indeed, research suggests that there is variability in degree of SCI pain interference among various racial groups, with non-whites tending to report more severe pain than whites. ${ }^{67}$ Similarly, it was not possible to compare SCI pain and no pain groups on potential aetiological variables that may contribute to pain (e.g. gender, marital status, injury severity, psychological morbidity) $)^{6,65,66}$ as studies did not consistently report these data for pain subgroups. Future SCI research might consider matching pain and no groups on these potential confounds.

The limited data prevented moderator analyses of the pain experience that may have led to qualifications in the results. This included the impact of potentially important within-group differences in pain duration and type, ${ }^{2,6}$ in addition to pre-existing differences in values and attitudes. Indeed, recent research suggests that a substantial proportion of individuals with persistent SCI pain modify their social activities because of pain perception resulting in a pain-dependent lifestyle. ${ }^{68}$

Finally, the reliance on cross-sectional data limits any causal inferences that can be established between pain and the examined 
psychosocial constructs. Longitudinal studies are needed to clarify whether the observed psychosocial differences are the cause, or result, of SCI pain, as well as whether the association between pain and psychosocial adjustment changes over time. Indeed, the presence of pain has been identified as the strongest predictor of poor psychological functioning and social integration for individuals with chronic SCI over a 6-year period. ${ }^{6}$

\section{CONCLUSION}

The present study highlights the utility of the ICF as a reference framework for understanding psychosocial difficulties in the experience of SCI pain. SCI pain is a complex and multifaceted construct, necessitating consideration of contextual factors when investigating pain onset and course. Early and accurate pain assessment, followed by targeted multidisciplinary intervention, is critical to reduce the personal and social burden of pain.

\section{DATA ARCHIVING}

There were no data to deposit.

\section{CONFLICT OF INTEREST}

The authors declare no conflict of interest.

\section{ACKNOWLEDGEMENTS}

We thank M Bell, research librarian at the University of Adelaide, for assistance with the electronic database searches. Acknowledgements also go to the authors of identified studies who provided additional statistical information on request.

References marked with an asterisk indicate studies included in the meta-analysis.

1 van Gorp S, Kessels AG, Joosten EA, van Kleef M, Patijn J. Pain prevalence and its determinants after spinal cord injury: a systematic review. Eur J Pain 2015; 19: 5-14.

2 Bryce TN, Biering-Sorensen F, Finnerup NB, Cardenas DD, Defrin R, Lundeberg T et al. International Spinal Cord Injury Pain Classification: Part I. Background and description. Spinal Cord 2012; 50: 413-417.

3 Widerstrom-Noga E, Biering-Sorensen F, Bryce T, Cardenas DD, Finnerup NB, Jensen MP et al. The International Spinal Cord Injury Pain Basic Data Set. Spinal Cord 2008; 46: 818-823.

4 Cardenas DD, Jensen MP. Treatments for chronic pain in persons with spinal cord injury: a survey study. J Spinal Cord Med 2006; 29: 109-117.

5 Cardenas DD, Felix ER. Pain after spinal cord injury: a review of classification, treatment approaches, and treatment assessment. Phys Med Rehabil 2009; 1: 1077-1090.

6 Jensen MP, Moore MR, Bockow TB, Ehde DM, Engel JM. Psychosocial factors and adjustment to chronic pain in persons with physical disabilities: a systematic review. Arch Phys Med Rehabil 2011; 92: 146-160.

7 Molton IR, Stoelb BL, Jensen MP, Ehde DM, Raichle KA, Cardenas DD. Psychosocial factors and adjustment to chronic pain in spinal cord injury: replication and crossvalidation. J Rehabil Res Dev 2009; 46: 31-42.

8 Cieza A, Kirchberger I, Biering-Sorensen F, Baumberger M, Charlifue S, Post MW et al. ICF Core Sets for individuals with spinal cord injury in the long-term context. Spinal Cord 2010; 48: 305-312.

9 Kirchberger I, Cieza A, Biering-Sørensen F, Baumberger M, Charlifue S, Post MW et al. ICF Core Sets for individuals with spinal cord injury in the early post-acute context. Spinal Cord 2010; 48: 297-304.

10 Geyh S, Muller R, Peter C, Bickenbach JE, Post MW, Stucki G et al. Capturing the psychologic-personal perspective in spinal cord injury. Am J Phys Med Rehabil 2011; 90: S79-S96.

11 *Nicholson Perry K, Nicholas MK, Middleton J. Spinal cord injury-related pain in rehabilitation: a cross-sectional study of relationships with cognitions, mood and physical function. Eur J Pain 2009; 13: 511-517.

12 Rodrigues D, Tran Y, Wijesuriya N, Guest R, Middleton J, Craig A. Pain intensity and its association with negative mood States in patients with spinal cord injury. Pain Ther 2013; 2: 113-119.

13 Taylor J, Huelbes S, Albu S, Gómez-Soriano J, Peñacoba C, Poole HM. Neuropathic pain intensity, unpleasantness, coping strategies, and psychosocial factors after spinal cord injury: an exploratory longitudinal study during the first year. Pain Med 2012; 13: $1457-1468$.
14 Craig A, Tran Y, Siddall P, Wijesuriya N, Lovas J, Bartrop R et al. Developing a model of associations between chronic pain, depressive mood, chronic fatigue, and self-efficacy in people with spinal cord injury. J Pain 2013; 14: 911-920.

15 Raichle KA, Hanley M, Jensen MP, Cardenas DD. Cognitions, coping, and social environment predict adjustment to pain in spinal cord injury. J Pain 2007; 8: 718-729.

16 Craig A, Wijesuriya N, Tran Y. The influence of self-efficacy on mood states inpeople with spinal cord injury. Int Sch Res Notices 2013; 2013: 6.

17 Donnelly C, Eng JJ. Pain following spinal cord injury: the impact on community reintegration. Spinal Cord 2005; 43: 278-282.

18 *Erosa NA, Berry JW, Elliott TR, Underhill AT, Fine PR. Predicting quality of life 5 years after medical discharge for traumatic spinal cord injury. Br J Health Psychol 2014; 19: 688-700.

19 Jensen MP, Hoffman AH, Cardenas DD. Chronic pain in individuals with spinal cord injury: a survey and longitudinal study. Spinal Cord 2005; 43: 704-712.

20 Gargaro J, Warren C, Boschen K. Perceived barriers and facilitators to community reintegration after spinal cord injury: a critical review of the literature. Crit Rev Phys Rehabil Med 2013; 25: 101-141.

21 Cripps RA, Lee BB, Wing P, Weerts E, Mackay J, Brown D. A global map for traumatic spinal cord injury epidemiology: towards a living data repository for injury prevention. Spinal Cord 2011; 49: 493-501.

22 Cohen J. A power primer. Psychol Bull 1992; 112: 155-159.

23 Lipsey MW, Wilson DB. Practical Meta-analysis. Sage Publications: London, UK, 2001.

24 *Norrbrink Budh C, Hultling C, Lundeberg T. Quality of sleep in individuals with spina cord injury: a comparison between patients with and without pain. Spinal Cord 2005; 43: 85-95.

25 *Norrbrink Budh C, Osteraker AL. Life satisfaction in individuals with a spinal cord injury and pain. Clin Rehabil 2007; 21: 89-96.

26 *Putzke JD, Richards J, Dowler RN. The impact of pain in spinal cord injury: a case-control study. Rehabil Psychol 2000; 45: 386-401.

27 *Putzke JD, Richards J, Hicken BL, DeVivo MJ. Interference due to pain following spinal cord injury: important predictors and impact on quality of life. Pain 2002; 100 231-242.

28 *Rintala DH, Loubser PG, Castro J, Hart KA, Fuhrer MJ. Chronic pain in a communitybased sample of men with spinal cord injury: prevalence, severity, and relationship with impairment, disability, handicap, and subjective well-being. Arch Phys Med Rehabil 1998; 79: 604-614.

29 * Rintala DH, Hart KA, Priebe MM. Predicting consistency of pain over a 10-year period in persons with spinal cord injury. J Rehabil Res Dev 2004; 41: 75-88.

30 *Ataoglu E, Tiftik T, Kara M, Tunc H, Ersoz M, Akkus S. Effects of chronic pain on quality of life and depression in patients with spinal cord injury. Spinal Cord 2013; 51 23-26.

31 *Barrett H, McClelland JM, Rutkowski SB, Siddall PJ. Pain characteristics in patients admitted to hospital with complications after spinal cord injury. well-being. Arch Phys Med Rehabil 2003; 84: 789-795.

32 *Elliot T, Harkins S. Psychosocial concomitants of persistent pain among persons with spinal cord injury. NeuroRehab 1991; 1: 9-18.

33 *Jensen MP, Hoffman AJ, Cardenas DD. Chronic pain in individuals with spinal cord injury: a survey and longitudinal study. Spinal Cord 2005; 43: 704-712.

34 *Lidal IB, Veenstra M, Hjeltnes N, Biering-Sorensen F. Health-related quality of life in persons with long-standing spinal cord injury. Spinal Cord 2008; 46: 710-715.

35 * Min JA. Resilience as a possible moderator for the relationship between pain and depression in patients with spinal cord injury. Asia Pac Psychiatry 2012; 4: 14.

36 *Tate DG, Forchheimer MB, Karana-Zebari D, Chiodo AE, Kendall Thomas JY. Depression and pain among inpatients with spinal cord injury and spinal cord disease: differences in symptoms and neurological function. Disabil Rehabil 2013; 35 1204-1212.

37 *Tonack M, Hitzig SL, Craven BC, Campbell KA, Boschen KA, McGillivray CF. Predicting life satisfaction after spinal cord injury in a Canadian sample. Spinal Cord 2008; 46: 380-385.

38 *Wang JC, Chan RC, Tsai YA, Huang WC, Cheng $\mathrm{H}$, Wu HL et al. The influence of shoulder pain on functional limitation, perceived health, and depressive mood in patients with traumatic paraplegia. J Spinal Cord Med 2015; 38: 587-592.

39 *Westgren N, Levi R. Quality of life and traumatic spinal cord injury. Am J Phys Med Rehabil 1998; 79: 1433-1439.

40 *Wollaars MM, Post MW, van Asbeck FW, Brand N. Spinal cord injury pain: the influence of psychologic factors and impact on quality of life. Clin J Pain 2007; 23: 383-391.

41 Moher D, Liberati A, Tetzlaff J, Altman DG. Preferred reporting items for systematic reviews and meta-analyses: The PRISMA Statement. Ann Intern Med 2009; 151: 264-269.

42 Hozo SP, Djulbegovic B, Hozo I. Estimating the mean and variance from the median, range, and the size of a sample. BMC Med Res Methodol 2005; 5: 13.

43 Wilson DB. Practical meta-analysis effect size calculator (Online calculator), George Mason University: Fairfax, VA, USA, 2001. Available at: www.campbellcollaboration. org/escalc/html/EffectSizeCalculator-Home.php.

44 Haidich AB. Meta-analysis in medical research. Hippokratia 2010; 14: 29-37.

45 Borenstein M, Hedges LV, Higgins JPT, Rothstein HR. Introduction to Meta-analysis. Wiley: New York, NY, USA, 2009.

46 Thompson B. Effect sizes, confidence intervals, and confidence intervals for effect sizes. Psychol Sch 2007; 44: 423-432.

47 Orwin R. A fail-safe N for effect size. J Educ Stat 1983; 8: 157-159. 
48 Higgins JPT, Thompson SG, Deeks JJ, Altman DG. Measuring inconsistency in metaanalyses. BMJ 2003; 327: 557-560.

49 Whitehurst DG, Engel L, Bryan S. Short Form health surveys and related variants in spinal cord injury research: a systematic review. J Spinal Cord Med 2014; 37: $128-138$.

50 Elfstrom ML, Ryden A, Kreuter M, Persson L-O, Sullivan M. Linkages between coping and psychological outcome in the spinal cord lesioned: development of SCL-related measures. Spinal Cord 2002; 40: 23-29.

51 Craig A, Tran Y, Middleton J. Psychological morbidity and spinal cord injury: a systematic review. Spinal Cord 2009; 47: 108-114.

52 Peter C, Müller R, Cieza A, Geyh S. Psychological resources in spinal cord injury: a systematic literature review. Spinal Cord 2012; 50: 188-201.

53 van Leeuwen CM, Kraaijeveld S, Lindeman E, Post MW. Associations between psychological factors and quality of life ratings in persons with spinal cord injury: a systematic review. Spinal Cord 2012; 50: 174-187.

54 Cao Y, Walker EA, Krause JS. Environmental barriers and subjective health among people with chronic spinal cord injury: a cohort study. J Spinal Cord Med 2015; 38: 526-531.

55 Murphy G, O'Hare M, Wallis L. The relationships among different types of social support accessed by traumatic spinal cord injury survivors. Int J Disabil Manage 2010; 5: 59-66.

56 van Leeuwen CM, Post MW, van Asbeck FW, van der Woude LH, de Groot S, Lindeman E. Social support and life satisfaction in spinal cord injury during and up to one year after inpatient rehabilitation. J Rehabil Med 2010; 42: 265-271.

57 Nicholas MK. Practice and procedures. In: Rice A, Justins D, Newton-John T, Howard RF, Miaskowski C (eds). Clinical Pain Management, 2nd edn. CRC Press, 2008, pp 95-106.

58 Barclay L, McDonald R, Lentin P, Bourke-Taylor H. Facilitators and barriers to social and community participation following spinal cord injury. Aust J Occ Ther 2013; 63: $19-28$
59 Middleton JW, Tate RL, Geraghty TJ. Self-efficacy and spinal cord injury: psychometric properties of a new scale. Rehabil Psychol 2003; 48: 281-288.

60 Dworkin RH, Turk DC, Farrar JT, Haythornwaite JA, Jensen MP, Katz NP et al. Core outcome measures for chronic pain clinical trials: IMMPACT recommendations. Pain 2005; 113: 9-19.

61 Ballert CS, Stucki G, Biering-Sørensen F, Cieza A. Towards the development of clinical measures for spinal cord injury based on the International Classification of Functioning, Disability and Health With Rasch Analyses. Arch Phys Med Rehabil 2014; 95: 1685-1694.

62 Kalpakjian CZ, Bombardier CH, Schomer K, Brown PA, Johnson KL. Measuring depression in persons with spinal cord injury: a systematic review. J Spinal Cord Med 2009; 32: 6-24.

63 González DA, Jenkins SR. Cross-measure equivalence and communicability in the assessment of depression. A focus on factor-based scales. Assessment 2014; 21: 731-741.

64 Bombardier CH, Richards JS, Krause JS, Tulsky D, Tate DG. Symptoms of major depression in people with spinal cord injury: implications for screening. Arch Phys Med Rehabil 2004; 85: 1749-1756.

65 Norrbrink Budh C, Lund I, Hultling C, Levi R, Werhagen L, Ertzgaard P et al. Gender related differences in pain in spinal cord injured individuals. Spinal Cord 2003; 41: $122-128$.

66 Cardenas DD, Bryce TN, Shem K, Richards JS, Elhefni H. Gender and minority differences in the pain experience of people with spinal cord injury. Am J Phys Med Rehabil 2004; 85: 1774-1781.

67 Fyffe DC, Deutsch A, Botticello AL, Kirshblum S, Ottenbacher KJ. Racial and ethnic disparities in functioning at discharge and follow-up among patients with motor complete spinal cord injury. Arch Phys Med Rehabil 2014: 95: 2140-2150.

68 Noreau L, Noonan VK, Cobb J, Leblond J, Dumont FS. Spinal Cord Injury Community Survey: A National, Comprehensive Study to Portray the Lives of Canadians with Spinal Cord Injury. Top Spinal Cord Inj Rehabil 2014; 20: 249-264.

Supplementary Information accompanies this paper on the Spinal Cord website (http://www.nature.com/sc) 